\author{
ANNALS OF “DUNAREA DE JOS” UNIVERSITY OF GALATI \\ MATHEMATICS, PHYSICS, THEORETICAL MECHANICS \\ FASCICLE II, YEAR X (XLI) 2018, No. 2
}

Article DOI: https://doi.org/10.35219/ann-ugal-math-phys-mec.2018.2.13

\title{
STUDY OF AIR QUALITY IN THE MUSEUM ENVIRONMENT. GALATI STUDY CASE
}

\author{
Adrian Roșu ${ }^{1}$, Daniel-Eduard Constantin ${ }^{1}$, Arseni Maxim ${ }^{1}$, Mihaela \\ Timofti $^{1}$, Mirela Voiculescu ${ }^{1}$, Bogdan Roşu ${ }^{1}$, Valentina Calmuc ${ }^{1}$, Alexandru \\ Iulian Chelmus ${ }^{2}$ \\ I"Dunarea de Jos", University of Galati, Faculty of Sciences and Environment, European Center of \\ Excellence for the Environment, Str. Domneasca, Nr.111, Galati 800008, Romania \\ ${ }^{2}$ National Institute of Optoelectronic - INOE 2000, Bucharest, Romania \\ e-mail address: adrian_rosu_90@yahoo.ro
}

\begin{abstract}
It is known that the conservation of cultural heritage requires that atmospheric parameters as temperature, humidity or radiation be constant and have well-defined values. Small deviations may irreversibly damage paintings, sculptures, jewels, textiles, etc. Also, air pollution (i.e. increased concentration of trace gases) may affect negatively the quality of artworks through direct and indirect corrosion effects. To our knowledge, such measurements have not been performed in local museums, for a sufficiently long time. This is the first study where we present measurements of temperature, humidity, and radiation, together with air quality measurements inside the Visual Art Museum of Galati city ( $45^{\circ} 26^{\prime} \mathrm{N}, 28^{\circ} 2^{\prime}$ " E), Romania. The results will be used in the future for the implementation of conservation and protection measures of artworks in museums.
\end{abstract}

Keywords: air pollution, artworks conservation, indoor pollution level, museum, cultural heritage

\section{INTRODUCTION}

The impact of pollution was first studied to investigate its effect on the human health [1], but starting with the 90s, the effect of pollutants on the cultural heritage has come to the attention of conservators and restorers [2]. Nowadays, particular attention is given to the preservation of mobile and immobile heritage assets. Due to the increase of polluting sources and air quality degradation, the degradation of artworks is difficult to monitor. [3]. Besides pollution, improper microclimate conditions of exposition or storage spaces have an important impact on the conservation status of various art works. Microclimate monitoring, together with studies conducted on the effects of indoor air pollution on objects, have received an increasing interest over the last decade [4. 5].

Means for identifying risks and evaluating the degradation rate are based on a complex, longterm monitoring process developed in the areas of interest. Results of such measurements can lead to relevant decisions and actions to minimize the possible damage caused by temperature, humidity, pollutants, and light on the objects exhibited in museums. Nowadays, the long-term monitoring is more accessible and precise, due to the development of intelligent sensorsSuch measurements are useful for finding the best conservation plan for the multitude of vulnerable organic materials, such as leather, wood, paper, silk, used to create heritage assets [6]. 
Temperature and relative humidity variations have the greatest effect on the conservation status of an object. These may induce stress and sometimes may trigger irreversible changes in the physical and chemical properties, with the final result of permanent damaging of the artwork. However, a constant but inappropriate microclimate may also be just as damaging [7]. The process of degradation is progressive and cumulative; therefore, on the one hand, museums must, respect rigorous conditions regarding indoor microclimate [8], and on the other, they must take into account the atmospheric pollution. The lifetime of pollutants in the air may vary from minutes to days [1]. High traffic and industry development contribute significantly to air pollution in urban areas, due to the production of particles and gaseous pollutants, such as nitrogen oxides, sulfur dioxide and ozone [4]. The depositing of atmospheric particles on surfaces of artistic interest can cause an unaesthetic impact while chemical reactions can damage them [3].

Most museums are historic buildings, whose structural characteristics affect the air exchange between outside and inside [8]. Also, their historic character sometimes does not allow the implementation of modern heating and ventilation solutions for the preservation of exposed heritage objects because these changes could affect the original appearance of the building. Depending on the possible sources of pollution in the building, in order to protect the artworks, the air inside needs to be recirculated as much as possible, and the incoming air flux from outside is kept to the minimum [4].

\section{METHODS AND DATA}

\subsection{Site}

The main objective of the experimental study was to evaluate the air composition inside the museum in the period 9 - 11 October 2018, using AEROQUAL monitors. The Museum of Visual Art (MVA) in Galați city, located at $45^{\circ} 26^{\prime} \mathrm{N}, 28^{\circ} 2^{\prime}$ " E (see Fig.1. a), was chosen for the study. One of the four stations that compose the local NAQMN (National Air Quality Monitoring Network), GL-2 is located relatively close to the museum (Fig.1. a). This contributed to choosing the museum for our monitoring campaign since the GL-2 air quality monitoring station can provide information about the outdoor atmospheric loading. Moreover, MVA is one of the few institutions in Galaţi city that has many valuable artwork and heritage objects. Another objective was to study the contribution and the impact of the air coming inside the museum that is richer in air pollutants because of the heavy road traffic from one of the main roads that pass by the MVA.
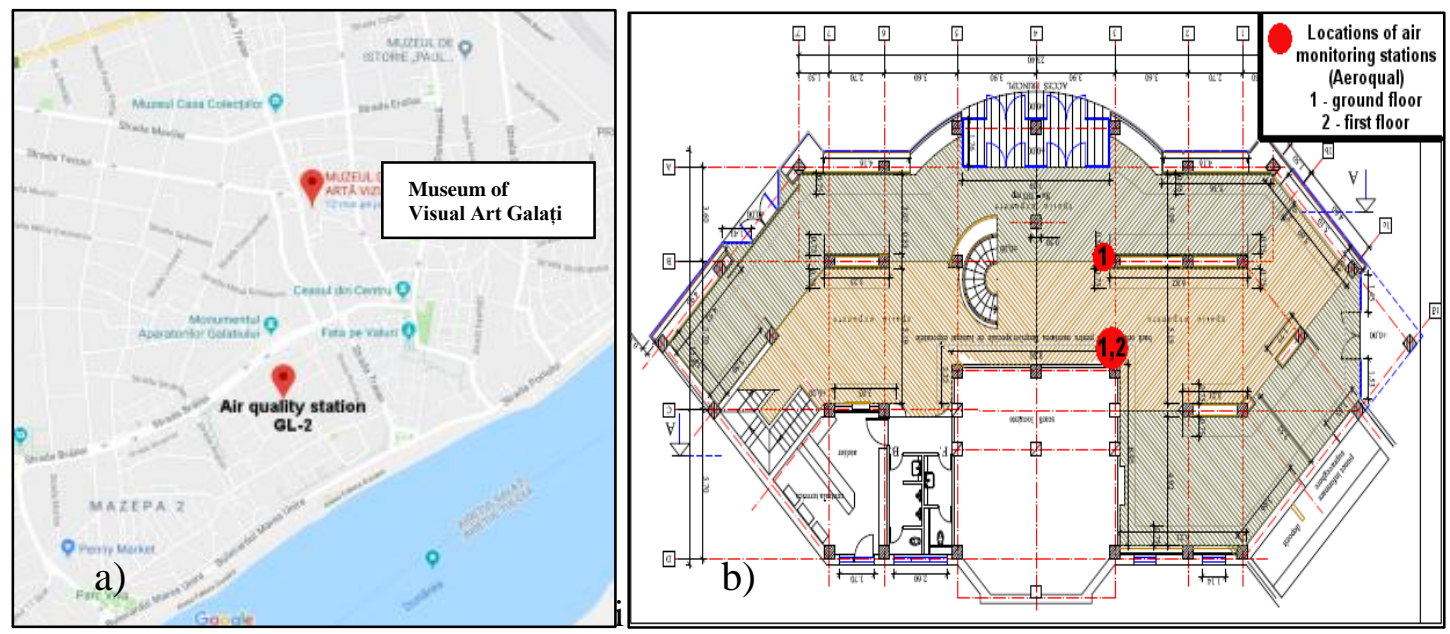

Fig.1. a. Location of MVA and GL-2 air quality monitoring stations. b. Locations of AEROQUAL monitors inside the MVA.

The equipment was based on 3 AEROQUAL compact air monitoring stations (shown in Fig.2.) that were placed inside the museum, on the ground and the first floors (see Fig.1. b and Fig.2.). The monitoring stations were placed close to the entrance of each floor. A parallel survey of the 
number of people entering and exiting the museum was performed hourly. Data of each atmospheric parameter recorded by the outdoor air quality monitoring station GL-2 was used in the analysis of the indoor measurement data.

\subsection{Equipment}

The characteristics of each sensor that composes the monitoring station are presented in Table 1 , together with the corresponding working time.

Table 1 Characteristics of the AEROQUAL sensors used in the monitoring campaign at MVA.

\begin{tabular}{|c|c|c|c|c|c|}
\hline Sensor used & $\begin{array}{c}\text { Trace } \\
\text { gas/Parameter }\end{array}$ & Range & Resolution & $\begin{array}{l}\text { Measurement } \\
\text { method }\end{array}$ & Time interval \\
\hline Ozone Sensor & $\mathrm{O}_{3}$ & $\begin{array}{c}0-0.5 \\
\text { ppm }\end{array}$ & $0.001 \mathrm{ppm}$ & $\begin{array}{l}\text { Gas Sensitive } \\
\text { Semiconductor } \\
\text { (GSS) }\end{array}$ & 10 - 11 Oct. 201812 AM - 12 PM \\
\hline Sulfur Dioxide Sensor & $\mathrm{SO}_{2}$ & $\begin{array}{l}0-10 \\
\text { ppm }\end{array}$ & $0.01 \mathrm{ppm}$ & $\begin{array}{l}\text { Gas Sensitive } \\
\text { Semiconductor } \\
\text { (GSS) }\end{array}$ & $\begin{array}{c}9 \text { Oct. } 20183 \text { PM - 11PM } \\
10 \text { Oct. } 201812 \mathrm{AM}-11 \mathrm{PM} \\
11 \text { Oct. } 201812 \mathrm{AM}-5 \mathrm{PM}\end{array}$ \\
\hline Nitrogen Dioxide & $\mathrm{NO}_{2}$ & $\begin{array}{l}0-1 \\
\text { ppm }\end{array}$ & $0.001 \mathrm{ppm}$ & $\begin{array}{l}\text { Gas Sensitive } \\
\text { Semiconductor } \\
\text { (GSS) }\end{array}$ & $\begin{array}{c}9 \text { Oct. } 20183 \mathrm{PM}-11 \mathrm{PM} \\
10 \text { Oct. } 201812 \mathrm{AM}-11 \mathrm{PM} \\
11 \text { Oct. } 201812 \mathrm{AM}-5 \mathrm{PM}\end{array}$ \\
\hline $\begin{array}{c}\text { Particulate Matter } \\
\text { Sensor }\end{array}$ & $\mathrm{PM}_{10}$ and $\mathrm{PM}_{2.5}$ & $\begin{array}{c}0.001- \\
1 \mathrm{ppb} \\
\end{array}$ & $0.001 \mathrm{ppb}$ & $\begin{array}{l}\text { Laser particle } \\
\text { counter (LPC) }\end{array}$ & 11 Oct. $201810 \mathrm{AM}-5 \mathrm{PM}$ \\
\hline $\begin{array}{l}\text { Temperature and } \\
\text { Relative Humidity } \\
\text { Sensor }\end{array}$ & $\begin{array}{c}\mathrm{T} \\
\mathrm{RH}\end{array}$ & $\begin{array}{c}40- \\
123.8 \\
{ }^{\circ} \mathrm{C} / \\
0-100 \% \\
\mathrm{RH}\end{array}$ & $\mid \begin{array}{c}0.01{ }^{\circ} \mathrm{C} \\
0.03 \% \mathrm{RH}\end{array}$ & $\begin{array}{c}(\text { CMOSens } \AA) \\
\text { technology } \\
(\mathrm{CMOS})\end{array}$ & $\begin{array}{l}9 \text { Oct. } 20183 \mathrm{PM}-11 \mathrm{PM} \\
10 \text { Oct. } 201812 \mathrm{AM}-11 \mathrm{PM} \\
11 \text { Oct. } 201812 \mathrm{AM}-5 \mathrm{PM}\end{array}$ \\
\hline
\end{tabular}

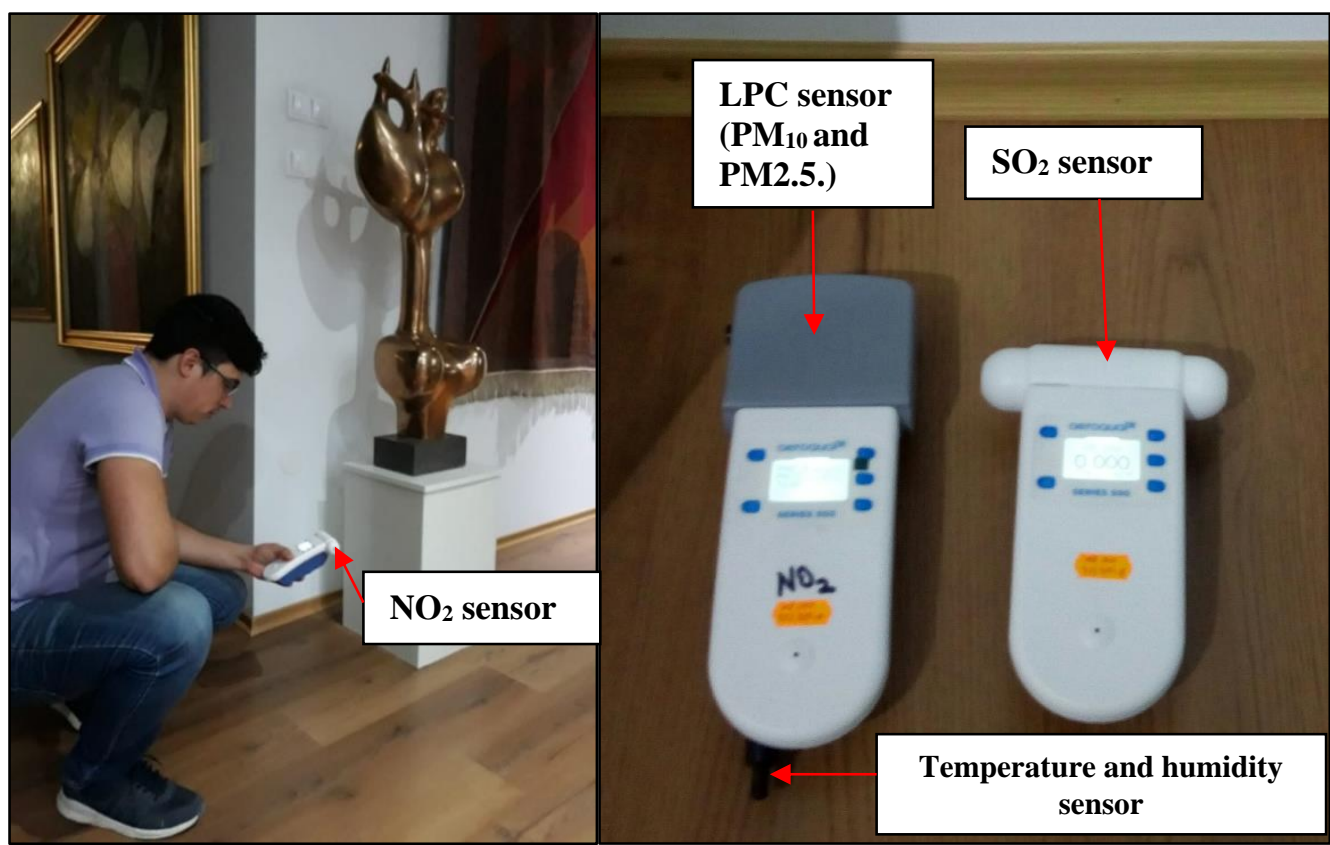

Fig.2. Installing the AEROQUAL monitors with different sensor type inside the MVA

The electrochemical method is used by the $\mathrm{NO}_{2}, \mathrm{SO}_{2}, \mathrm{O}_{3}$ sensors as a redox reaction caused by the effects of electric current, usually through an electrode, in an enclosure called an electrochemical cell (shown in Fig.3. a). The reaction of the environment with the electrode causes changes in the state of oxidation that lead to a variation in its resistance to the electrical current, this 
variation of resistance leads to a variation in the amount of current, which is proportional to the amount of chemical compound with which it has reacted with the electrode. The signal of the electrode is translated into concentrations through a transducer (processor).

The LPC(Light Particle Counter) sensor (Fig.3. b) used for quantifying $\mathrm{PM}_{10}$ and $\mathrm{PM}_{2,5}$, this sensor uses a method that is based either on light scattering or light beam obfuscation. A highintensity light source is used to illuminate the particle as it passes through the detection chamber. The particle passes through the light source (usually a laser or halogen light) and if light scattering is used, the redirected light is detected by a CCD detector. If the light blocking (obturation) is used, the light loss is detected. The amplitude of the light scattered or blocked by light is measured, and the particles are counted and sorted into standardized counting sizes.
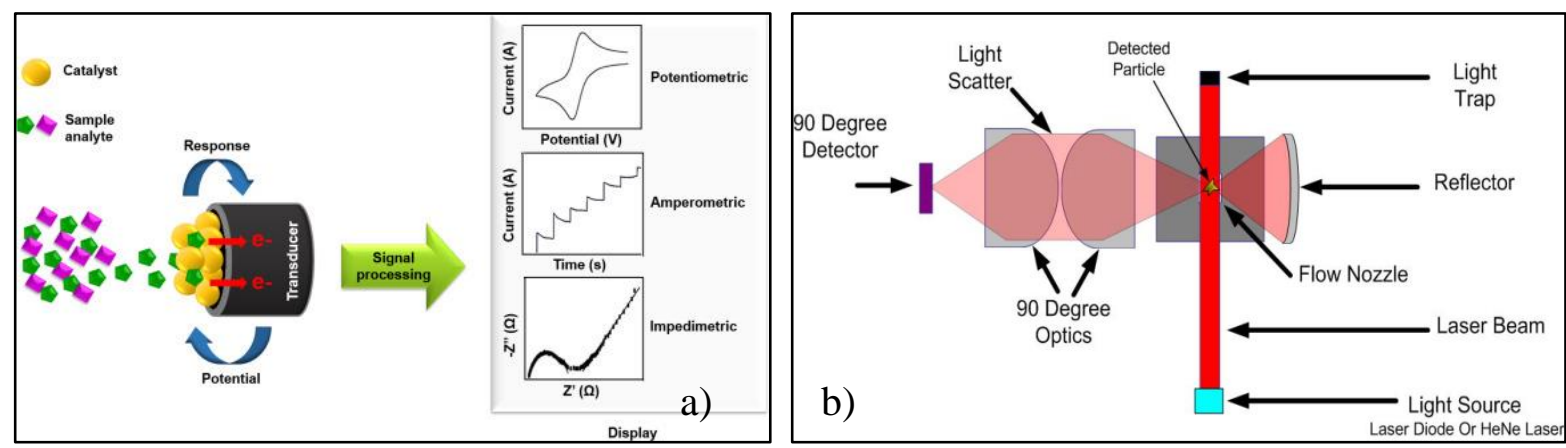

Fig.3. a. The principle of the electrochemical sensors (adapted after [10]. $b$. The principle of the LPC sensors adapted after [11].

The CMOS technology of the temperature and humidity sensor has two modes of operation, in which either the temperature or the humidity is converted into a digital code representing a frequency ratio between two oscillators. This ratio is determined by the ratios of the timing capacitances and bias currents in both oscillators. The reference oscillator is biased by a current whose temperature dependency is complementary to the proportional absolute temperature (PTAT) current. For the temperature measurement, this results in an exceptional normalized sensitivity of about $0.01 \% /{ }^{\circ} \mathrm{C}$ at the accepted expense of reduced linearity. The humidity sensor is a capacitor, whose value varies linearly with relative humidity $(\mathrm{RH})$ with a normalized sensitivity of $0.03 \% / \%$ $\mathrm{RH}$.

\section{RESULTS AND DISCUSSION}

The following air quality parameters were monitored inside the Museum: $\mathrm{NO}_{2}, \mathrm{SO}_{2}, \mathrm{O}_{3}$, $\mathrm{PM}_{10}, \mathrm{PM}_{2.5}$, Temperature, and Relative Humidity). Additionally, measurements for the same period from the outdoor monitoring station GL-2 were obtained from [12]. The direct comparison of data showed no conclusive results so all the data were normalized to the maximum in order to obtain a more clear picture. Also, the number of people entering and exiting the museum every hour was considered in order to have some information of air flow from outdoor to indoor. During the campaign, all concentrations for all monitored atmospheric pollutants were smaller than the legal limits.

The variation of $\mathrm{NO}_{2}$ and $\mathrm{SO}_{2}$ in Fig.4. show that the concentration of both trace gases increased indoors after approximately one hour after opened the door of the museum, which allows the outside air to enter inside the building. Also, the peaks of indoor $\mathrm{NO}_{2}$ follow the outdoor $\mathrm{NO}_{2}$ maxima in most cases, except the afternoon of Oct $10^{\text {th. }}$ This suggests that the reasons for increased $\mathrm{NO}_{2}$ inside the Museum are indeed the door opening, and not a poor insulation, allowing polluted air from outside to creep inside. $\mathrm{NO}_{2}$ peaks can be observed around $9 \mathrm{AM}, 10 \mathrm{AM}$ and $6 \mathrm{PM}$, when the maximum flow of outdoor air occurs during visitors entering and exiting the museum. 
The indoor $\mathrm{SO}_{2}$ level to increased exposure to inflowing polluted air from outside is also clear since the indoor $\mathrm{SO}_{2}$ does not follow strictly the $\mathrm{SO}_{2}$ concentration given by the GL2 station. Their outside concentration shows practically no significant peaks, but a relatively constant level. Thus both $\mathrm{NO}_{2}$ and $\mathrm{SO}_{2}$ in the Museum respond to the incoming flux from outside. A solution to this would be a two-step entrance.

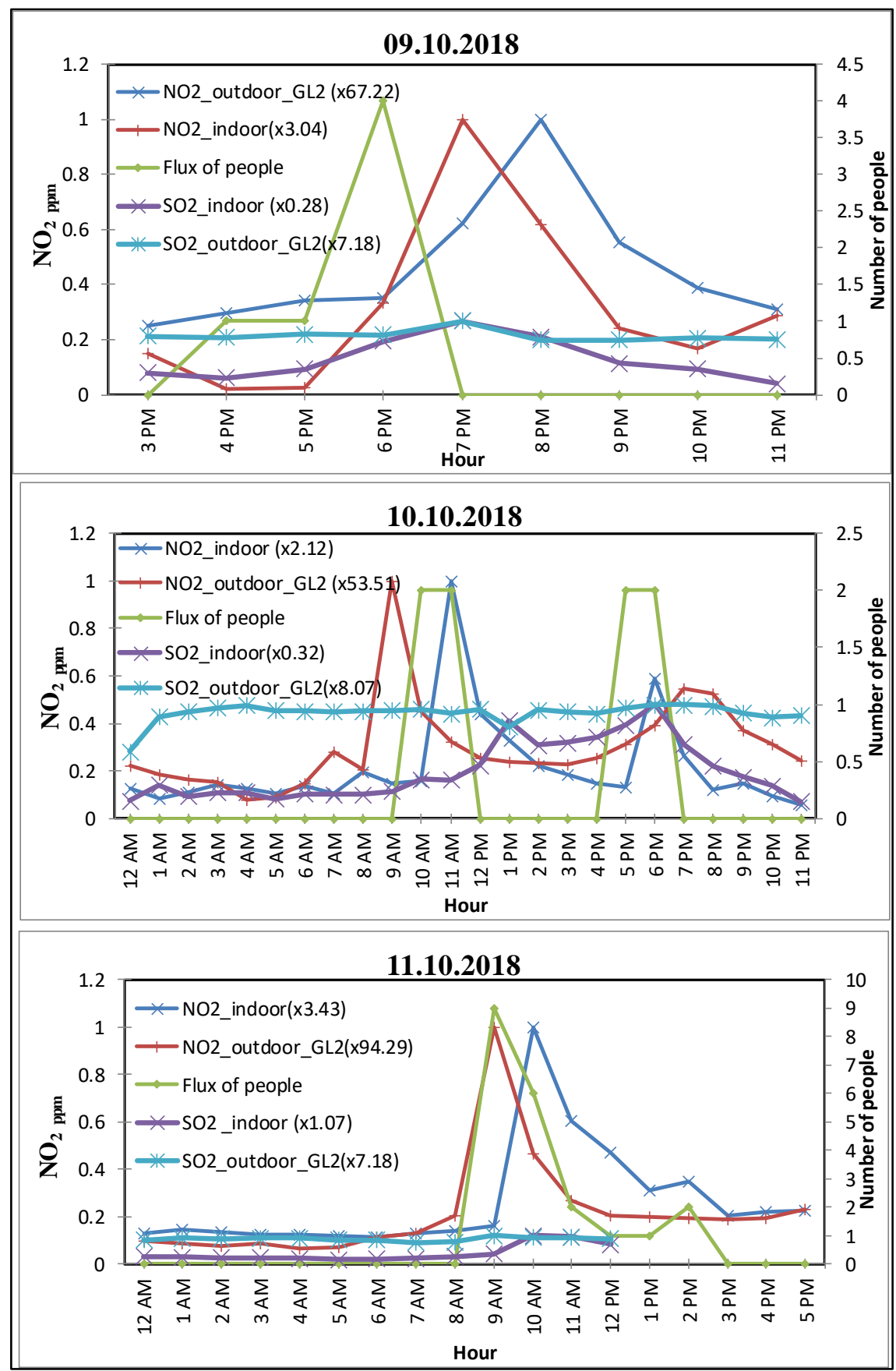

Fig.4. Variation of NO2 and SO2 indoor (blue, cross, purple, cross) and outdoor GL-2 measurements (red, plus, blue, asterisk) and the flux of people (green, circle) entering and exiting MVA.

The ozone sensor was used in the period $10-11$ October at the monitor located at ground level near the entrance. The sensor is less sensible and the results are not reliable as the sensor recorded very small concentration of ozone inside the museum during visiting hours only after approximately one hour when outdoor air entered the museum as a cause of door opening. The ozone 
recorded data is presented in Fig.5. A more sensitive technique like chemiluminescence or DOAS is needed in order to obtain more accurate and conclusive results.

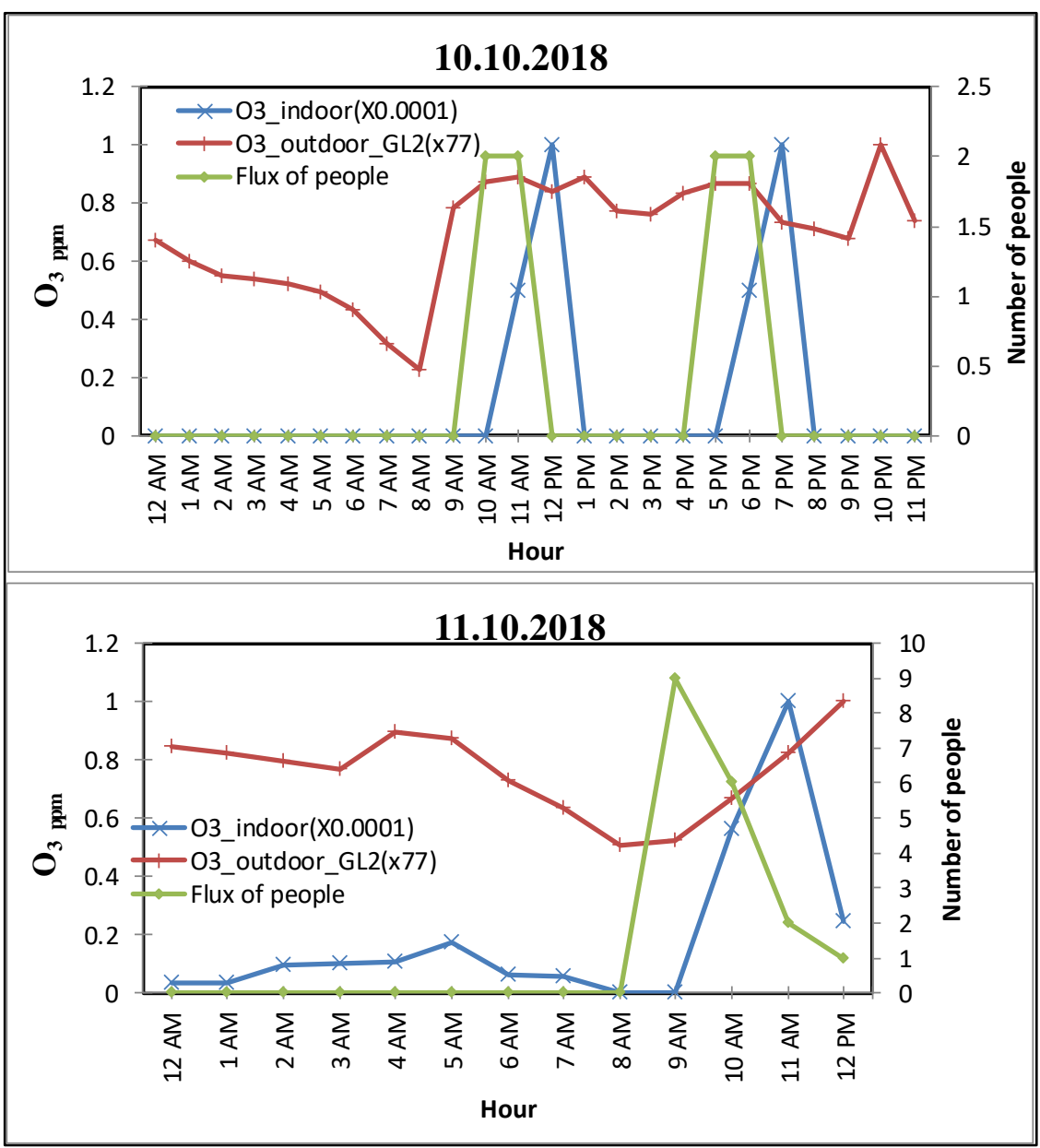

Fig.5. Variation of the indoor (blue, cross) and outdoor (red, plus) $\mathrm{O}_{3}$ and the flux of people (green, diamond)

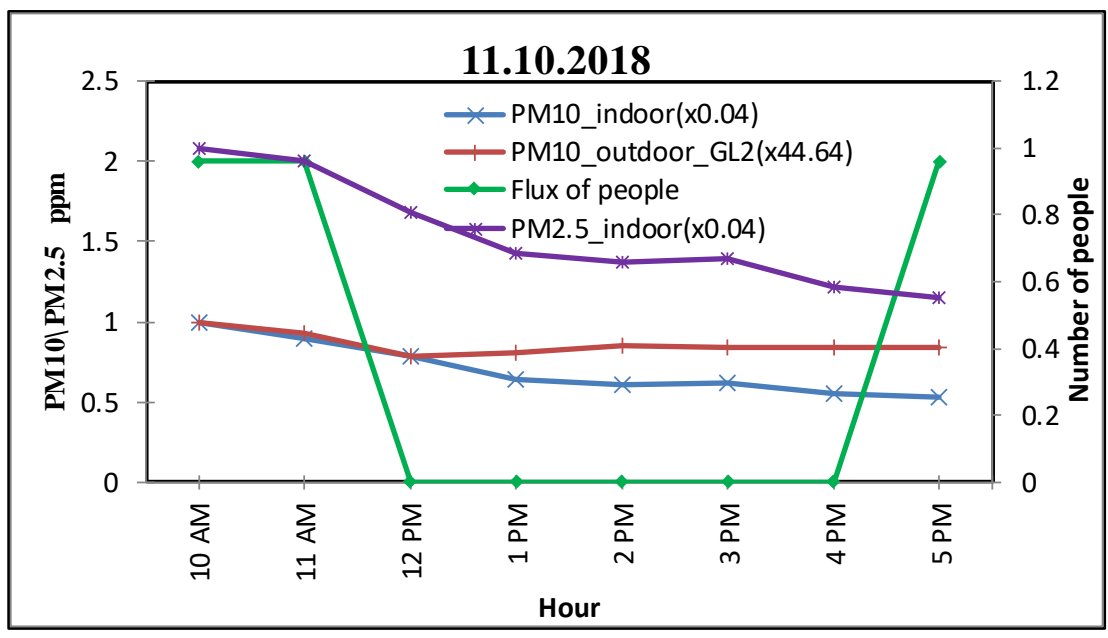

Fig.6. Variation of the indoor (blue, cross) and outdoor (red, plus) PM10 concentrations, indoor PM2.5 (purple, asterisk), and the flux of people (green, diamond). No data was available for GL -2 measured PM2.5 
The sensor used for recording of particulate matter was used only on 11 October from 10 AM to 5 PM. The data is presented in Fig.6, which shows no clear effect on the indoor concentration of the particulate matter when the outdoor air is entering the museum. The outdoor and indoor trends of the particulate matter $\left(\mathrm{PM}_{10}, \mathrm{PM}_{2.5}\right)$ are decreasing during measurements.

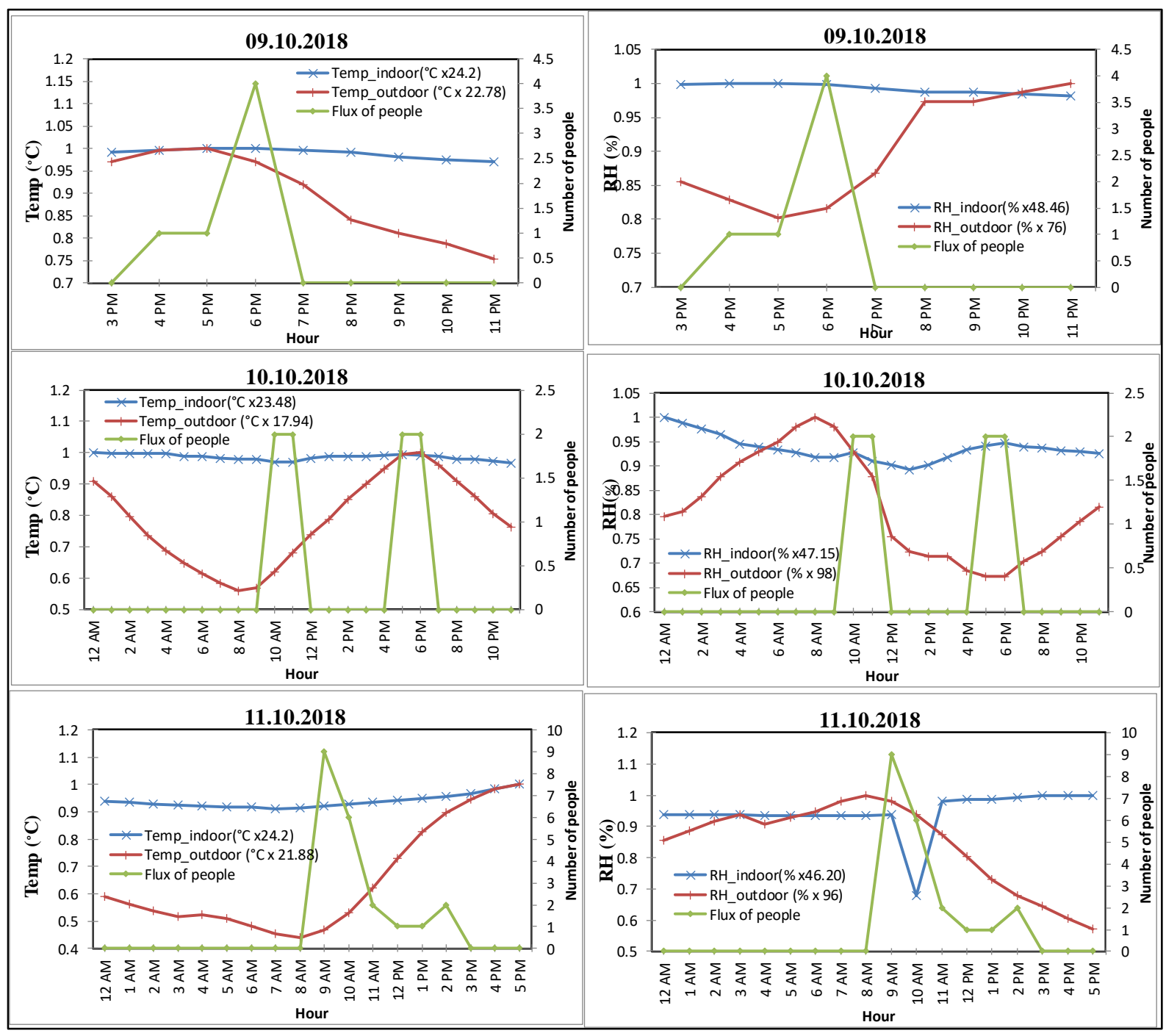

Fig.7. Variation of the indoor (blue, cross) and outdoor (red, plus) measurements for Temperature (left) and Humidity (right) and the flux of people (green, diamond)

Data for temperature and relative humidity are presented in Fig.7. and show that the museum has a very good air conditioning system. The indoor parameters are constant, despite incoming people (thus exposure to potential variations). The drop in humidity on Oct 11-that may be associated with a response to incoming airflow, but this the humidity obviously restored rapidly.

\section{CONCLUSIONS}

The results of the experimental study performed in the Visual Art Museum of Galaţi in the period 9 - 11 October 2018 showed that the indoor level of $\mathrm{NO}_{2}$ and $\mathrm{SO}_{2}$ may change in response to the door opening. The other sensors $\left(\mathrm{O}_{3}, \mathrm{PM}_{10}, \mathrm{PM}_{2.5}\right)$ measurements are more or less conclusive on how the airflow from the outside can influence the quality of the air inside the museum. Results on temperature and relative humidity sensors showed a steady state with no major variation of air inside the museum. Thus, due to an input of air pollutants $\left(\mathrm{NO}_{2}\right.$ and $\left.\mathrm{SO}_{2}\right)$ and a relatively high humidity 
(more than 40\%) indirect influence to the cultural heritage objects can occur by the formation of small acid particles that can cause damage to wood, leather and pigments [13]. In order to obtain more information, a more accurate and advanced technique as chemiluminescence (with a higher measurement resolution and a lower limit of detection) or LP DOAS (Long Path Differential Optical Absorption Spectroscopy) must be applied [14].

\section{Acknowledgment}

This work was supported by a grant of the Romanian Ministery of Research and Innovation, CCCDI - UEFISCDI, project number PN-III-P1-1.2-PCCDI-2017-0878/NR. 55PCCDI/2018, within PNCDI III.

\section{References}

1. Stefano Paolo Corgnati, Valentina Fabi, Marco Filippi. A methodology for microclimatic quality evaluation in museums: Application to a temporary exhibit. Building and Environment, Volume 44, Pages 1253-1260, ISSN 0360-1323, 2009.

2. Hua Li, Tafeng Hu 1, Wenting Jia, Junji Cao, Suixin Liu, Rujin Huang, Tao Ma, Na Xi. Evaluation of Policy Influence on Long-Term Indoor Air Quality in Emperor Qin's TerraCotta Museum, China. Atmosphere, Volume 6, Pages 474-489, ISSN 2073-4433, 2016.

3. Anna Worobiec, Lucyna Samek, Agnieszka Krata, Katleen Van Meel, Barbara Krupinska, Elżbieta Anna Stefaniak, Paweł Karaszkiewicz, René Van Grieken. Transport and deposition of airborne pollutants in exhibition areas located in historical buildings-study in Wawel Castle Museum in Cracow, Poland. Journal of Cultural Heritage, Volume 11, Issue 3, Pages 354-359, ISSN 1296-2074, 2010.

4. Paul Lankester and David Thickett. Climate for Collections Standards and Uncertainties 2013. Edited by Jonathan Ashley-Smith, Andreas Burmester and Melanie Eibl, Chapter Delivering damage functions in enclosures, Doerner Institut London; pp. 339, ISBN: 978-300-042252-2, 2013.

5. Susana Lopez-Aparicio, Terje Grøntoft, Elin Dahlin, Air quality assessment in cultural heritage institutions using ewo dosimeters, 9th Indoor Air Quality meeting (IAQ) Chalon-surSaône, France, 21-23, ISSN: 1581-9280, April 2010.

6. Elin DAHLIN, Preventive conservation strategies for organic objects in museums, historic buildings and archives, 5th conference report "cultural heritage research: a Pan European challenge". Krakovia. 16-18th de May, 2002.

7. Stefano Paolo Corgnati, Valentina Fabi, Marco Filippi. A methodology for microclimatic quality evaluation in museums: Application to a temporary exhibit, Building and Environment, Volume 44, Issue 6, Pages 1253-1260, ISSN 0360-1323, 2009.

8. Joanna Ferdyn-Grygierek. Indoor environment quality in the museum building and its effect on heating and cooling demand, Energy and Buildings, Volume 85, Pages 32-44, ISSN 0378, 2014.

9. Eder, C., Valente, V., Donaldson, N., Demosthenous, A. A cmos smart temperature and humidity sensor with combined readout. Sensors, 14(9), 17192-17211, 2014.

10. Omar, F. S., Duraisamy, N., Ramesh, K., \& Ramesh, S. Conducting polymer and its composite materials based electrochemical sensor for Nicotinamide Adenine Dinucleotide (NADH). Biosensors and Bioelectronics, 79, 763-775, 2016.

11. https://en.wikipedia.org/wiki/File:Particlecounter.jpg

12. www.calitateaer.ro (accessed on 12.10.2018)

13. Camuffo, Dario. Microclimate for cultural heritage: conservation, restoration, and maintenance of indoor and outdoor monuments. Elsevier, 2013. 
14. Pttts Jr, J. N., Wallington, T. J., Biermann, H. W., \& Winer, A. M. Identification and measurement of nitrous acid in an indoor environment. Atmospheric Environment (1967), 19(5), 763-767, 1985. 